\title{
Stability of response strength hierarchies in continued word association'
}

BURTON G. ANDREAS, UNIVERSITY OF ROCHESTER
MICHAEL MILLS, WASHINGTON UNIVERSITY

Selected stimulus items were repeated in a booklet testing continued word associations. Ss had been instructed to treat any such recurrence as a new encounter, neither trying consciously to repeat nor to avoid repeating their earlier responses. Slightly fewer than half of the original responses were repeated by individuals, although total production was about the same. Correlations indicated high stability of common response probabilities and low to moderate stability of ordinal positions of responses.

An earlier investigation (Andreas, 1966) demonstrated the feasibility of determining stimulus meaningfulness $(\mathrm{m})$, common response probability (p), and median ordinal position of common responses (o) in a single administration of a continued word association task. The determination of stimulus meaningfulness $(\mathrm{m})$ is conducted in general accordance with the procedure developed by Noble (1952). The study of response probabilities ( $p$ ) parallels the work of Bilodeau \& Howell (1965). The present study sought to determine the stability of response strength hierarchies as revealed in these indicants when certain stimuli were repeated in the test booklet.

\section{Method}

Ss were 35 summer session students from the University of Delaware who were paid for participating.

Continued word association testing was accomplished by having responses written in a test booklet. Each booklet page presented a single five-letter stimulus item of CVCVC format, either word or paralog. Each item was repeatedly mimeographed on its page in two triple-spaced columns of ten repetitions each.

Three stimulus items placed in the first half of the test booklet were repeated in the second half. These were MELON, MAYIR, and NUSIR. This set of items occurred first, in varied permutations of order, on pages 3,6 , and 9 . The second occurrence of these repeated items was on pages 12,15 , and 18 , also in varied orders. Eighteen different sequences of these items were used to minimize order effects and to vary separation of a repetition from its original presentation from a minimum of 2 to a maximum of 14 intervening pages. All other pages of the 20-page booklet were buffer items, words and paralogs, in many different nonsystematic sequences. Being extraneous to the purpose of the experiment, these 14 buffer items were not included in any data tabulations.

General instructions were taken verbatim from Noble's (1952, p. 425) report. In order to forestall confusion arising when a $\mathrm{S}$ encountered a repeated stimulus, and to try to eliminate any very strong set to repeat-or avoid-earlier responses, the following sentences were added: "Some of the items may be repeated in your booklet. If you do happen to find a stimulus item repeated, pretend that it is a new stimulus. Don't try to remember what you put down the first time and don't try to purposely omit previous responses."

The testing procedure incorporated the Andreas (1966) modifications of the Noble (1952) method, eliminating practice pages, rest period, and interitem interval. Ss were merely told to "turn the page" at the end of each minute.

\section{Results}

The results of the experiment, for the repeated stimulus items, are presented in Tables 1 and 2. Table 1 lists all responses given commonly (down to $\mathrm{p}=.20$ ) on either the first or second encounter with the stimulus item. For each encounter, the table shows the probability (relative frequency) of response occurrence and the median ordinal position of occurrence. At the right of the table is shown, for each response

Table 1. Probabilities of Occurrence $(p)$, Median Ordinal Position $(o)$, and Per Cent Repetition of the Commonest Responses. $\mathbf{N}=\mathbf{3 5}$.

\begin{tabular}{|c|c|c|c|c|c|c|}
\hline \multirow[t]{2}{*}{ Stimulus } & \multirow[t]{2}{*}{ Response } & \multicolumn{2}{|c|}{$\begin{array}{l}\text { First } \\
\text { Encounter }\end{array}$} & \multicolumn{2}{|c|}{$\begin{array}{l}\text { Second } \\
\text { Encounter }\end{array}$} & \multirow[t]{2}{*}{$\begin{array}{l}\text { Per Cent } \\
\text { Repetition }\end{array}$} \\
\hline & & $p$ & 0 & $p$ & $o$ & \\
\hline \multirow[t]{13}{*}{ MELON } & watermelon & .77 & 1.21 & .80 & 1.50 & 74 \\
\hline & canteloupe & .46 & 2.38 & .60 & 4.13 & 81 \\
\hline & honeydew & .40 & 3.10 & .38 & 3.33 & 78 \\
\hline & fruit & .34 & 3.50 & .29 & 4.83 & 50 \\
\hline & green & .34 & 7.50 & .26 & 6.75 & 42 \\
\hline & seed & .34 & 6.50 & .38 & 5.25 & 67 \\
\hline & rind & .26 & 5.00 & 11 & 6.55 & 45 \\
\hline & eat & .23 & 4.00 & .20 & 7.00 & 50 \\
\hline & sweet & .23 & 4.50 & .20 & 4.75 & 62 \\
\hline & juice & .20 & 6.25 & .23 & 5.83 & 62 \\
\hline & red & .20 & 7.00 & .11 & 6.00 & 43 \\
\hline & ripe & .20 & 5.75 & .20 & 7.25 & 71 \\
\hline & round & .20 & 7.00 & .09 & 2.25 & 14 \\
\hline \multirow[t]{5}{*}{ MAYIR } & mayor & .77 & 1.34 & .77 & 1.06 & 85 \\
\hline & May & .38 & 3.25 & .14 & 4.75 & 31 \\
\hline & may & .31 & 2.67 & .26 & 3.33 & 55 \\
\hline & year & .26 & 3.00 & .14 & 2.33 & 40 \\
\hline & ear & .23 & 3.50 & .17 & 2.17 & 86 \\
\hline \multirow[t]{7}{*}{ NUSIR } & sir & .57 & 3.30 & .57 & 2.79 & 60 \\
\hline & new & .51 & 4.70 & .31 & 3.00 & 28 \\
\hline & music & .46 & 1.30 & .31 & 2.00 & 44 \\
\hline & noose & .31 & 4.00 & .23 & 4.00 & 64 \\
\hline & nurse & .31 & 1.75 & .26 & 1.14 & 91 \\
\hline & news & .23 & 3.00 & .26 & 4.25 & 38 \\
\hline & nuisance & .23 & 1.90 & .17 & 2.50 & 25 \\
\hline
\end{tabular}


Table 2. Indices of Stability of Response Hierarchies

Stimulus Items Presented Twice MELON MAYIR NUSIR

\begin{tabular}{|c|c|c|c|}
\hline $\begin{array}{l}\text { Meaningfulness }(m) \\
\text { on First Presentation } \\
\text { Meaningfulness }(m)\end{array}$ & 10.06 & 6.40 & 6.00 \\
\hline $\begin{array}{l}\text { on Second Presentation } \\
\text { Per Cent of First }\end{array}$ & 9.94 & 7.23 & 6.40 \\
\hline $\begin{array}{l}\text { Production Repeoted } \\
\text { Correlation of Common }\end{array}$ & 48.9 & 45.1 & 42.4 \\
\hline $\begin{array}{l}\text { Response Probabilities } \\
\text { Correlation of Median }\end{array}$ & +.92 & +.89 & +.87 \\
\hline $\begin{array}{l}\text { Positions of Common Responses } \\
\text { Correlation of Positions }\end{array}$ & +.40 & +.56 & +.19 \\
\hline $\begin{array}{l}\text { of All Repeated Responses } \\
\text { Median Correlation of Individuals' }\end{array}$ & +.49 & +.49 & +.57 \\
\hline Response Positions & +.55 & +.80 & +.69 \\
\hline
\end{tabular}

given initially, the percent of Ss repeating it at the second encounter with the stimulus item.

In Table 2 are shown several indices of the stability of the response hierarchies from one stimulus presentation to the next. The first line of entries gives baseline data on meaningfulness ( $m$ ) defined as the mean number of responses given to the stimulus item in $1 \mathrm{~min}$. The second line of entires contains $\mathrm{m}$ values derived from $\mathrm{Ss}^{\prime}$ second encounter with the stimuli. It might seem that Ss gave a near-identical set of responses each time, thus generating about the same $\underline{m}$ values. However, the next entries indicate that just under 50 percent of the first responses were repeated.

Correlational indices comprise the final entries of Table 2. A product-moment correlation assessment of the stability of common response probabilities shows it to be quite high from one stimulus presentation to the next. These correlations of $p$ and $\underline{o}$ values were based on an extended Table 1 which carried down to $p=.14$ for either response period. The median ordinal positions of responses a re not quite as stable, yielding only low to moderate correlations. Considered independently, only the value of +.40 for responses to MELON approximates statistical significance $(p=.05)$. Going back beyond medians to the ordinal positions of all responses repeated by individual $\mathrm{Ss}$, we find slightly higher values, ranging from +.49 to +.57 . Additional evidence for some stability of an individual's response hierarchy was found by obtaining correlations based on each individual's ordering of his repeated responses. The medians of such individual correlations are given as the last line of entries in Table 2. Discussion

Continued word association, in contrast to discrete word association, offers two or more ways of examining the concept of "response strength hierarchy." In discrete association the single responses yield only a set of relative frequencies of response occurrence.
In contrast, continued association adds the ordinal position at which a $\mathrm{S}$ makes a particular response and the median ordinal position at which a common response occurs in a group's production of associations. In this study, then, we have assessed the stability of response strength hierarchies from these several points of view.

The stability of common response probabilities was found to be quite high. This is the case despite the fact that fewer than half of the Ss, on the average, repeated any given response. When some Ss failed to repeat a response, other Ss introduced it on the second stimulus encounter, thus tending to maintain the response probability hierarchy.

A lesser stability of hierarchy is found in the ordinal position data, especially in the group median values. However, these three correlations, derived from truncated sets of data, are in agreement in their indication of some stability of response sequence. Further, the correlations based on individuals' ordinal response positions yield more basic evidence of stability of the response hierarchy in sequence of production.

The most questionable aspect of this investigation of stability of response hierarchies may be in the attempt to induce through instructions a set to treat the second encounter with a stimulus as though it were the first. Despite the injunction against purposely repeating-or avoiding-earlier responses, some Ss may have leaned toward these modes of reacting. In an effort to see how these tendencies may affect observed indices of response hierarchy stability, further research will be undertaken. In the planned experiment, two contrasting sets of instructions will be added. In one, Ss will be urged to repeat exactly the responses given to any stimulus if it is encountered a second time. In the other, Ss will be told to avoid repeating any earlier responses to a stimulus. The data should indicate how adequately Ss can remember a prior sequence of responses over several minutes of intervening responding to buffer items.

\section{References}

Andreas, B. G. Indicants of response strength hierarchies in continued word association. Psychon. Sci., 1966, 6, 447-448.

Bilodeau, E. A., \& Howell, D. G. Free association norms by discrete and continued methods. Washington, D. C.: Office of Naval Research, 1965.

Noble, C. E. An analysis of meaning. Psychol. Rev., 1952, 59, 421-430.

Noble, C. E., \& Parker, G. V. C. The Montana scale of meaningfulness (m). Psychol. Rep., 1960, 7, 325-331.

\section{Note}

1. This study was conducted while the senior author was Distinguished Visiting Professor at the Supporting Research Laboratory, U. S. Army Human Engineering Laboratories, Aberdeen Proving Ground, Maryland. The cooperation extended by Dr. John D. Weisz, Chief, and members of his staff is gratefully acknowledged. 